\title{
Pénfigo foliáceo: caso clínico
}

Pemphigus foliaceus: report of a case

\section{Resumen}

Se presenta un caso clínico de Pénfigo foliáceo en un varón de 34 años de edad derivado al Hospital Arzobispo Loayza, donde es evaluado y sometido a diferentes exámenes complementarios para dar el diagnóstico y tratamiento. El Pénfigo foliáceo se incluye dentro de las enfermedades ampollares, considerada una variedad crónica y relativamente benigna del pénfigo, donde el estado general del paciente se afecta muy poco. Se plantea que es una enfermedad auto inmune de etiología desconocida, que se caracteriza por presentar depósitos de auto-anticuerpos: Inmunoglobulinas y complemento en las uniones intercelulares. Como todo profesional de la salud el odontólogo debe tener conocimiento de las características clínicas generales y bucales para contribuir en el diagnostico diferencial de la enfermedad.

\begin{abstract}
This is a case report a case of Pemphigus Foliaceus in a 34 year-old male referred to the Arzobispo Loayza Hospital, which was evaluated and subjected to different examinations for diagnosis and treatment. Pemphigus Foliaceus is included in the blistering diseases, which is considered a chronic and relatively benign variety of pemphigus, where the patient's general condition is affected very little.

It is considered as an autoimmune disease of unknown etiology that is characterized by deposition of auto-antibodies: Immunoglobulins and complement to the intercellular junctions. As any health professional, the dentist must have knowledge of the clinical and general mouth to help in the differential diagnosis of the disease.
\end{abstract}

\section{Introducción}

Pénfigos son consideradas aquellas enfermedades ampollosas intraepidérmicas; que constituyen el grupo más importante de dermatosis ampollares en términos de morbilidad y mortalidad. Éstas presentan pérdida de unión entre las células intraepidérmicas (acantolisis). Inmunopatológicamente se caracterizan por la presencia de autoanticuerpos circulantes contra proteinas presentes en los desmosomas que conforman la unión intercelular. Existen varias formas de pénfigos, en relación a la clínica y el tipo de anticuerpo detectado. Las dos formas más conocidas de pénfigo: vulgar y foliáceo, se deben a la presencia de anticuerpos contra los componentes del desmosoma, concretamente la desmogleina 3 y 1 respectivamente. En este reporte nos referiremos al pénfigo foliáceo.

El Pénfigo Foliáceo es una enfermedad ampollar cutánea autoinmunè, esta forma de pénfigo es una forma menos severa de la enfermedad, en la cual la ampolla se forma a un nivel más superficial de la epidermis. Se caracteriza por la presencia de ampollas superficiales subcorneales $y$ autoanticuerpos de tipo Ig $G$ que son específicos para la región extracelular de la glicoproteína desmosomal desmogleina 1, encargada de la unión entre células epidérmicas. ${ }^{1,2}$

Se ha observado que un factor en la patogenia del pénfigo es el ambiental. Así, la ocupación predominante de los afectados fue la de agricultor y que en áreas endémicas es propia de varones; pero no es infrecuente observarla en mujeres; cabe resaltar que esta actividad laboral implica una exposición intensa a factores ambientales, incluyendo insectos hematófagos. ${ }^{3}$

Los focos endémicos se presentan casi exclusivamente en áreas rurales. El primer reporte de pénfigo foliáceo endémico en el Perú fue realizado por Heimgartner, en 1976, en cuatro

\section{Juana Delgadillo Ávila,' Adelmo Cuentas Robles, ${ }^{2}$ Carlos Campodonico ${ }^{3}$ y Melissa Barra Hinostroza. ${ }^{4}$}

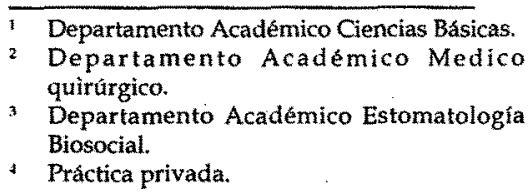

Correspondencia:

Juana Delgadillo Ávila

Calle Ramon Cerdeira 175, San Borja, Lima Perú

Teléfono: 225-1845

Correo electrónico juanidelgadillo@

Hotmail.com

Palabras Clave: Caso clínico, Pénfigo foliáceo.

Key words: Case report, Pemphigus foliaceus.

casos en Puerto Inca (Huánuco), ${ }^{4} \mathrm{EI}$ segundo, en 25 casos, en Requena y Ucayali. $^{s}$

\section{Aspectos clínicos generales}

La enfermedad afecta generalmente a personas entre 30 y 60 años, pero en su forma endémica se presenta también en adolescentes, suele tener un curso lento, pero también puede tener una instauración rápida presentándose las lesiones descamativas de forma abrupta y dando la imagen de dermatitis exfoliativa. ${ }^{6}$

Comienza local e insidiosamente. Clínicamente las lesiones del pénfigo foliáceo suelen ser ampollas superficiales que se rompen con facilidad dejando áreas de la piel denudadas, localizándose con mayor frecuencia en cara, cuero cabelludo, (existen reportes que han asociado esta manifestación con un mal pronóstico de la enfermedad), cuello y parte posterior del tronco. No se acompaña de lesiones mucosas. ${ }^{78}$ 


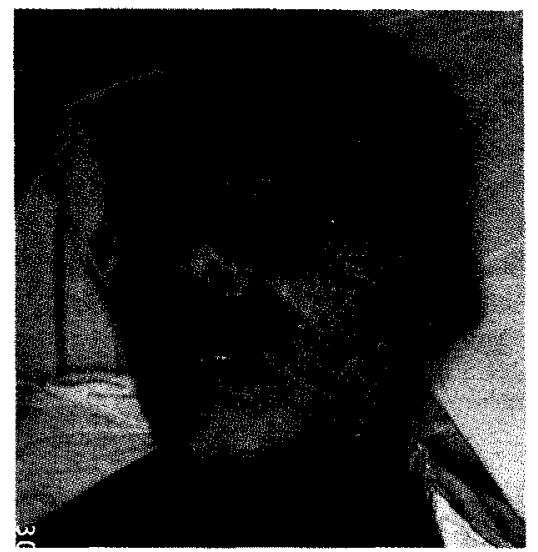

Fig. 1. En cara: lesiones hiperqueratócicas en cuello adenopatías.

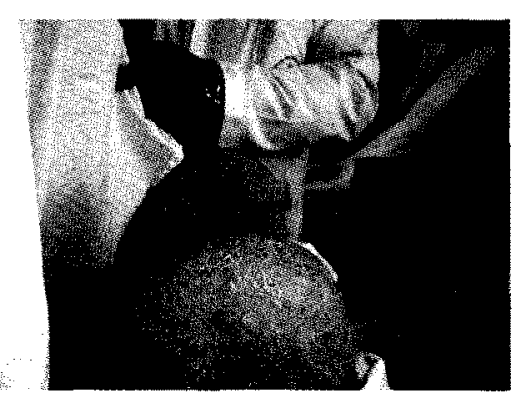

Fig. 2. Lesiones hiperqueratócicas en rodillas.

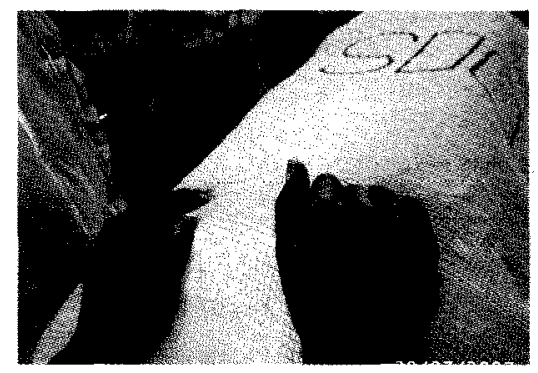

Fig. 3. En dorso se palpan lesiones hiperqueratócicas.

Histología. El principal hallazgo histológico en el pénfigo vulgar es la acantólisis justo por debajo del estrato córneo y en la capa granular. La histología del pénfigo foliáceo es similar a la del pénfigo vulgar, siendo la ampolla más superficial produciéndose al nivel de la capa granular de la epidermis.

\section{Caso clínico}

Paciente mestizo, masculino, de 34 años de edad, natural de Huánuco, sin antecedentes patológicos, que acude al hospital Arzobispo Loayza, después de varias consultas en su lugar de trabajo, en la selva de Ucayali.

Paciente refiere que su enfermedad comenzó hace un año, cuando ingresaba a la selva virgen para hacer labores de trocha.
Refiere que primero le apareció una lesión descamativa pruriginosa de más o menos dos $\mathrm{cm}$ en la región geniana derecha, para después extenderse por toda la cara, luego al cuero cabelludo, por lo que acude a un médico particular donde le diagnostican hongos, recetándole cremas pero sin mejoria del cuadro. Informa que siguió sus labores agrícolas, pero con el transcurso de los meses se ha ido extendiendo en todo el cuerpo, las lesiones crecen y son de color rojizo. Refiere prurito intenso. Dice que hace 6 meses se le irrita la piel por el calor. En los últimos tres meses las lesiones se extienden presentándose descamaciones espontáneas, acude varias veces a posta de salud y le indican transferencia a hospital de Lima. Refiere también fiebre y pérdida de peso.

\section{Examen clínico general (Fig. 1-4)}

Al examen clínico presenta en piel y anexos, lesiones hiperqueratósicas descamativas múltiples, en toda la superficie corporal, afectando plantas y palmas, sobre base eritematosa, con mal olor.

Sistema Óseo-Mio-Articular: Rangos articulados conservados, limitación funcional por dolor de lesiones en regiones de pliegues.

Sistema Linfático: Sin adenopatías. Cuello: $\operatorname{Sin}$ adenopatías.

Tórax y Pulmones: Tórax con múltiples lesiones descamativas.

Abdomen: Región abdominal cubierta por lesiones hiperqueratósicas.

Auscultación: RHA +, no doloroso a la palpación.

\section{Percusión: Timpanismo.}

\section{Cabeza:}

Cráneo: Normocéfalo; Conjuntivas: pálidas; Ojos: simétricos; Córneas: sin opacidades; Pupilas: fotoreactivas; $\mathrm{Ca}$ bello: lesiones descamativas en cuero cabelludo; Parpados: sin ptosis; Nariz: fosas nasales permeables; Ódos: CAE permeable.

\section{Exámenes complementarios}

Se realizan diferentes exámenes como: hemograma completo, antibiograma, urocultivo, examen completo de orina, examen parasitológico seriado, creatinina, urea completo, resultando determinante la biopsia de piel para el diagnostico definitivo: Pénfigo foliáceo.

\section{Tratamiento}

El empleo de los corticosteroides y la llegada de los fármacos inmunosupresores han mejorado de forma impresionante la prognosis de los enfermos de pénfigo. El tratamiento es similar al del pénfigo vulgar sin embargo no es necesario que sea muy intenso, con lo que se evita los efectos secundarios propios de la terapéutica corticosteroidea oral prolongada en la mayor parte de los casos; el empleo razonable de los esteroides tópicos o de la terapéutica inmunosupresora o de ambos casos puede evitar el recurrir a la prednisona oral. En el caso del pénfigo foliaceo, dado que la enfermedad puede permanecer localizada durante muchos años. puede ser suficiente el tratamiento con corticoides tópicos. ${ }^{9}$

\section{Evaluación odontológica}

Se observa lesiones hiperqueratósicas descamativas múltiples, en toda la superficie facial que se extiende por el dorso, no doloroso y no sangrante corporalmente.

Al examen clínico odontológico se observa borde eritematoso de mediana intensidad en el margen gingival de los dientes. También se observa pequeñas cavidades pigmentadas en las piezas $1.7,1.6,1.4,2.7,3.5,4.6$ y 4.8 .

En la pieza 4.3 se observa pérdida de esmalte del sector vestibular.

Se observa mal posición dentaria. El resto de estructuras de la boca se presentan con características normales.

\section{Diagnóstico}

Pénfigo Foliáceo. Gingivitís marginal generalizada. Lesiones cariosas múltiples en piezas $17,16,14,35,46$ y 48 . Fractura Coronal en pieza 34. Oclusión alterada.

\section{Discusión}

El pénfigo foliáceo es una enfermedad ampollar cutánea autoinmune, que es la forma relativamente benigna del pénfigo, que aparece generalmente en personas adultas con edades comprendidas entre 30 y 60 años. Falabella plantea que puede presentarse en jóvenes y en tal caso el pronóstico es más benigno $^{10}$ de etiología desconocida que se caracteriza por presentar depósitos de autoanticuerpos: inmunoglobulinas y complemento en las uniones intercelulares. ${ }^{7,10}$ 
Epidemiologicamente se presenta en todo el mundo sin una prevalencia racial o étnica, presentándose focos endémicos casi exclusivamente en áreas rurales.

En Brasil la forma endémica se conoce como "Fogo Selvagen", pero esta enfermedad también ha sido identificada en su forma endémica en Colombia, Paraguay, Perú, Túnez y Venezuela. En el Perú se ha informado de casos en la selva alta y selva baja, ${ }^{2,5,11,12}$

Diversos hallazgos epidemiológicos sugieren que la producción de autoanticuerpos patogénicos en personas con

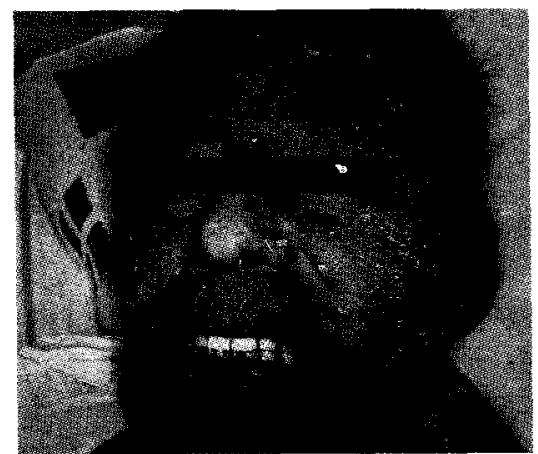

Fig. 4. Boca: Mucosa oral húmeda, labios con lesiones ampulares descamativas.

La enfermedad se caracteriza por presentar lesiones descamativas en la cara, incluyendo los labios pero principalmente se caracteriza por no presentar lesiones en las mucosas, por ello a diferencia del pénfigo vulgar no hallaremos erosiones o ulceraciones sobre la superficie de la mucosa bucal. En el pénfigo vulgar se observa con frecuencia lesiones en la mucosa de los paladares duro y blando. Las lesiones asientan fundamentalmente en la cara cuello, cuero cabelludo y parte del tronco, al contrario del pénfigo vulgar, suelen respetar las mucosas. ${ }^{7,8}$

La explicación a esto es que en el del pénfigo foliáceo las ampollas se producen al nivel de la capa granular de la epidermis. En estos pacientes existen anticuerpos dirigidos contra la desmogleina 1, que se expresa en los niveles más altos de la epidermis. La desmogleina está presente en la cavidad oral, pero estos pacientes nunca desarrollan lesiones orales ya que también existe la expresión la desmogleina 3 y esta desmogleina es capaz de mantener las células unidas incluso si se afecta la desmogleina. ${ }^{1,2,13}$

El odontólogo debe conocer, identificar y correlacionar los signos clínicos para poder diferenciar el pénfigo foliaceo del pénfigo vulgar.

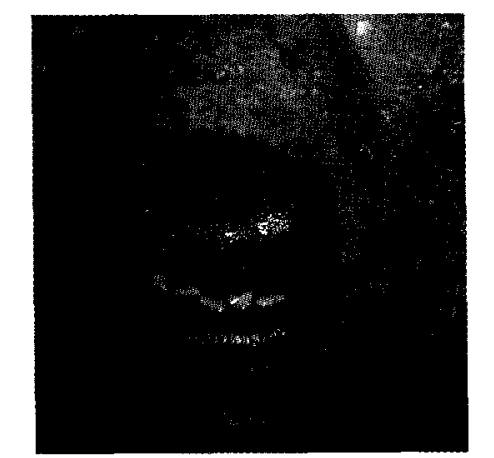

la enfermedad estaría vinculada a la exposición a uno o varios antígenos ambientales. ${ }^{1,13,14,15}$

Generalmente el pénfigo foliáceo puede tener un curso lento, evolucionando a la cronicidad en algunos años, aunque en ocasiones la instauración de las lesiones descamativas es abrupta y dan una imagen de dermatitis exfoliativa debido a la poca apariencia de las ampollas.,10,16 Clínicamente las lesiones del pénfigo foliáceo suelen ser erosiones superficiales con eritema, escamas y costras, pueden haber pequeñas ampollas que se forman a un nivel más superficial de la epidermis. ${ }^{6}$

\section{Conclusiones}

1. Se presenta un caso de pénfigo foliáceo en un paciente de 34 años.

2. Predominaron lesiones hiperqueratósicas descamativas múltiples, en toda la superficie corporal, afectando plantas y palmas sobre base eritematosa.

3. Se presentan lesiones eritematoescamosas discretamente exudativas en la frente y las mejillas.

4. El cuadro cutáneo fue de instalación lenta y paulatina, sin presencia de lesiones en la mucosa bucal

\section{Referencias bibliográficas.}

1. Warren S, Lin MS, Giudice G, Hoffman $R, y$ cols. The prevalence of antibodies against desmoglein 1 inendemic pemphigus foliaceus in Brazil. $N$ Eng J Med. 2000; 343:23-30.

2. Díaz LA, Arteaga LA, Hilario-Vargas $\mathrm{J}$, et al. Anti-desmoglein-1 antibodies in onchocerciasis, leismaniasis and Chagas disease suggest a possible Etiological link to fogo selvagem. J Invest Dermatology. 2004; 123:10451051.

3. Gonzáles F, Sáenz AM, Cirocco A; Tacaronte IM, y cols. Endemic pemphigus foliaceus in Venezuela: Report of two children. Pediatric Dermatology. 2006; 23:132-135.

4. Heimgartner $E, V$ de Heimgartner Experiencias en enfermedades dermatológicas endémicas en la selva peruana: Leishmaniasis y pénfigo foliáceo endémico. Med Cut ILA. 1976: 1:1-6.

5. Castillo A, Maguiña C. Pénfigo foliáceo variedad fuego salvaje en la selva peruana. Bol Soc Per Med Int.1993. 6:65-67.

6. Rook A, Wilkinson DS, Ebling F JG. Tratado de dermatología. 4ta ed. Barcelona: Doyma. 1989. 193-205.

7. Stanley JR. Pemphigus. En: Freedberg $\mathrm{IM}$, Eisen $\mathrm{AZ}$, Austen $\mathrm{KF}$, y cols Dermatology in general medicine. 6 ta ed. New York: Mc Graw-Hill. 2003 1:558-567.

8. Mc Kee P. Pathology of the skin London: Gower Medical Publishing. 1990: Falta páginas.

9. Basset N. Dapsone in initial treatement of superficial pemphigus. Arch dermatol 1987; $123: 783$

10. Giraldo N, Escobar C. Enfermedades vésico-ampollosas. En: Falabella R, Escobar C, Giraldo N. Dermatología. 5 ta ed. Bogotá: Corporación para Investigaciones Biológicas. 1997:401 413

11. Galarza C, Ronceros G, Mendoza D y cols. Pénfigo foliáceo endémico en el Departamento de Ucayali, Perú Reporte de 16 casos. An Fac Med Lima. 2002; 63:19-24.

12. Galarza, Willy Ramos, Gerardo Jiménez Gerardo Ronceros, Jorge Hancco, Jesús Díaz, Isabel Rojas y col. Pénfigo foleaceo endémico en el Perú: caracterización clinica, epidemiológica e inmuno patológica. Dermatología Peruana 2006 Vol 16(3) 219

13. Hans-Filho G, dos Santos V, Katayama JH, Aoki V, y cols. An active focus of high prevalence of fogo selvagem on an Amerindian reservation in Brazil. J Invest Dermatol. 1996;107:68-75.

14. Diaz LA, SampaioSA, Rivitti EA, Martins $C R$, y cols. Endemic pemphigufoliaceus (fogo selvagem). II. Current and historic epidemiologic studies. J Invest Dermatol. 1989;92:4-12

15. Lombardi C, Borges PC, Chaul A, Sampaio SA, Rivitti EA, Friedman $\mathrm{H}_{\text {, }}$ y cols. Enviromental risk factors in endemic pemphigus foliaceus (fogo selvagem). The Cooperative Group on Fogo Selvagem Research. J Inv Dermatol. 1992; 98:847-50.

16. Guillén C, Botella R, Sanmartín D. Manual Janssen de enfermades de la piel. Barcelona: Masson. 1996: 112-116.

Fecha de recepción: 15 abril 2009

Fecha de aceptación: 10 julio 2009 